From the Department of Microbiology and Epizootology,

College of Veterinary Medicine, Helsinki, Finland.

\title{
The Prevalence and Level of Colonisation by Mycoplasma Dispar and other Mycoplasmas on Calf Rearing Farms
}

\author{
By $R$. Tanskanen
}

Tanskanen, R.: The prevalence and level of colonisation by Mycoplasma dispar and other mycoplasmas on calf rearing farms. Acta vet. scand. 1987, 28, 209-226. - The prevalence and level of colonisation by respiratory mycoplasmas, especially by Mycoplasma dispar (M. dispar), in calves on 24 Finnish calf rearing farms were studied by using nasal swabs. A minimum of 5 calves from each farm was examined and $91.3 \%$ of the 206 calves examined were 1 to 5 months old. Nine herds were selected on account a diagnosed respiratory disease problem, the others without anamnestic knowledge of their health condition.

All 24 farms and $96.1 \%$ of the calves examined were found to harbour one or more species of mycoplasma. M. dispar, M. bovirhinis and Acholeplasma laidlawii were isolated from 23,19 and 3 farms or from $91.7,51.9$ and $3.4 \%$ of the calves investigated, respectively.

The prevalence for $\mathrm{M}$. dispar was $97.8 \%$ and the geometric mean titer $4.9 \log _{10}$ color changing units (ccu) among 1- to 5-month old calves belonging to the infected farms. The prevalence in the age-group of 6-to 12 -month old calves was significantly lower $(40 \%)$. No significant difference was found in the level of colonisation by M. dispar among the one-month age-groups of the 1- to 5-month old calves. A high degree of colonisation among 1- to 2-month old calves was indicative of the high ability of $\mathrm{M}$. dispar to spread and colonise the respiratory pathway of young calves in the conditions described. The same state still prevailing in calves aged 4 to 5 months supported the concept of a relatively long duration of a heavy colonisation by this mycoplasma. The prevalence of $\mathrm{M}$. bovirhinis among 1to 5-month old calves was lower than that of M. dispar. Any decrease in the level of colonisation of M. bovirhinis could not be demonstrated in older calves. The titer levels of both M. dispar and M. bovirhinis as well as the prevalence of M. bovirhinis were significantly higher in herds having a current respiratory disease problem than in healthy or mildly affected herds. The same relationship applied to the husbandry method of common pens as compared with individual pens. A causal relationship of increased colonisation level, either as cause or effect, to the respiratory disease is suggested, as well as a probably more indirect one to the common pen husbandry type.

Mycoplasma infections; mycoplasmosis in cattle; respiratory diseases of cattle; husbandry methods, epidemiology. 


\section{Introduction}

Examination of pneumonic lungs in several countries has indicated that mycoplasmas are frequent inhabitants of the diseased respiratory tract of calves (Gourlay et al. 1970, Bitsch et al. 1976, Yamamoto et al. 1976, Kuniyasu et al. 1977, Langford 1977, Bryson et al. 1978b, Munster et al. 1979, Bocklisch et al. 1983, Friis \& Krogh 1983). The most commonly isolated species have been Mycoplasma dispar (M. dispar), Ureaplasma spp., M. bovirhinis and M. bovis. Some other species have been isolated, although less frequently.

Experimental studies in gnotobiotic calves have shown that M. bovis, M. dispar and Ureaplasma spp. all are, to varying degrees, pathogenic for the respiratory tract (Gourlay et al. 1976, 1979, Howard et al. 1976). The question of a possible causal association of M. bovirhinis with calf pneumonia remains open and has not been supported by experiments with gnotobiotic calves (Gourlay et al. 1979).

The role and significance of mycoplasmas in the bovine respiratory disease complex in field conditions remains only poorly understood. In particular, epidemiological studies of the subject have been largely lacking. The present study applies such an approach.

In Finland, the first isolations of M. dispar, M. bovirhinis and Acholeplasma laidlawii (A. laidlawii) from the respiratory tract of calves were reported in papers describing the colonisation of the respiratory tract of calves by M. dispar (Tanskanen 1983, 1984).

The aim of the present survey was to obtain field information of the frequency and level of colonisation by respiratory mycoplasmas, particularly M. dispar, on Finnish calf rearing farms, and to investigate possible causal associations.

\section{Material and methods}

Nasal swab specimens were collected once from each of 24 calf rearing farms during the period of March 1982 to February 1984. Eighteen ( $75 \%$ ) farms were sampled during the winter (November to March), the remainder in the spring and autumn. The location of the farms is given in Fig. 1. A total of 20 veterinarians collected the specimens.

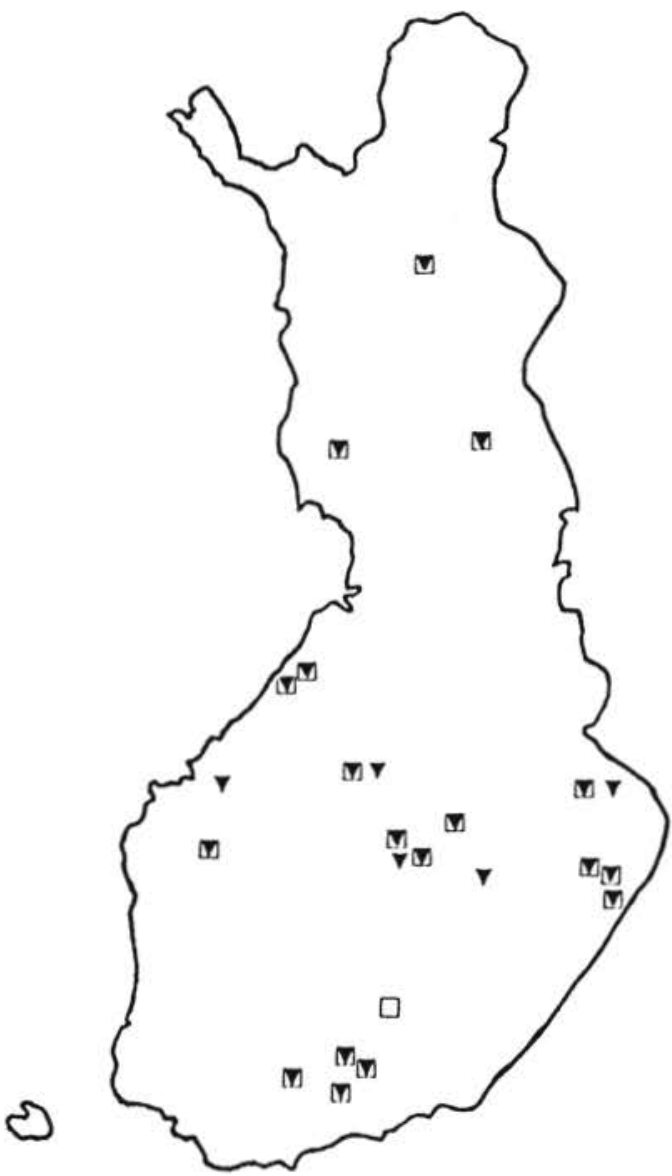

Figure 1. The location in Finland of the 24 farms studied. Farms found infected by: $\boldsymbol{\nabla}$ M. dispar, $\square \mathrm{M}$. bovirhinis and $\nabla$ both. 


\section{Selection and classification of farms}

The veterinarians who agreed to cooperate in the study haphazardly selected 15 calf rearing farms, each from their own locality. The selection was made from among farms on which no immediate anamnestic knowledge of the health condition of the calves was available. On 9 of these farms no evidence of the respiratory disease was observed by the veterinarian when collecting the specimens; nor had the disease been noticed by the owner in the several preceding months. On 6 farms symptoms of a mild respiratory illness, with occasional coughing and nasal discharge in some of the calves, was noticed by the veterinarian collecting specimens; or it has been noticed by the owner during the preceding months. No treatment of the calves was, however, prescribed by the veterinarian. This latter group will be classified as farms affected with "mild" respiratory disease.

The study subsequently covered an extra 9 farms based on the criterion of a respiratory problem requiring treatment by the local veterinarian. The veterinarians with knowledge of the research project in progress requested examination of specimens for diagnostic and curative purposes. These 9 farms are classified as having an epidemic of "severe" respiratory disease. Except for farms nos. 23 and 24 , the pattern was that of a chronic herd disease, affecting young (2- to 5 -month old) calves most seriously and with the highest incidence. The disease had lasted for a few weeks before the specimens were taken, the calves having undergone previous treatment by the veterinarian. On each of the farms nos. 2, 11, 12, 13, 20 and 22,2 to 8 calves had died during the course of the disease. Especially on farms nos. 2, 12, 13 and 22 , diarrhoea in varying degrees still accompanied, or had accompanied, the respiratory disease. On farms nos. 23 and 24 , the disease had the character of an acute outbreak, which affected all the age-groups of calves in a similar manner and with high frequency. The frequency of calves showing recognisable symptoms on the diseased farms was not estimated at the time of the specimen collection.

All the farms purchased calves for fattening from dairy stocks in the surrounding districts, usually at the age of 4 to 6 weeks, (the range was from 2 weeks to 3 months). Generally the calves arrived in batches of 5 to 20 , or occassionally even fewer. The number of calves on the farms varied from 9 to 120 (Table 1).

\section{Selection of calves}

There was no previous knowledge of the prevalence of M. dispar in this country. The initial aim of the study was to secure reliable information on the frequency of infected calf rearing farms. Only later and on the basis of the first results, and still in the phase of collating material, did the interest widen to cover some determinant-specific variations of the level of colonisation as well. Owing to the initial aim of the study, the age-group of calves principally sampled was the one expected to have the highest level of colonisation by M. dispar on the basis of the results of experimental colonisation and transmission studies (Tanskanen 1983, 1984, 1987a). The method of sampling was, however, judged to be suitable for the latter purposes. The veterinarians collecting the samples were told that the main target group was calves that had lived on the farm for at least 2 to 3 weeks and were under 6 months of age. Older calves could be sampled occasionally. On farms affected with severe disease the sampling primarily covered clinically affected calves; but also others could be sampled. Due to a reported high incidence in the age-group primarily sampled 


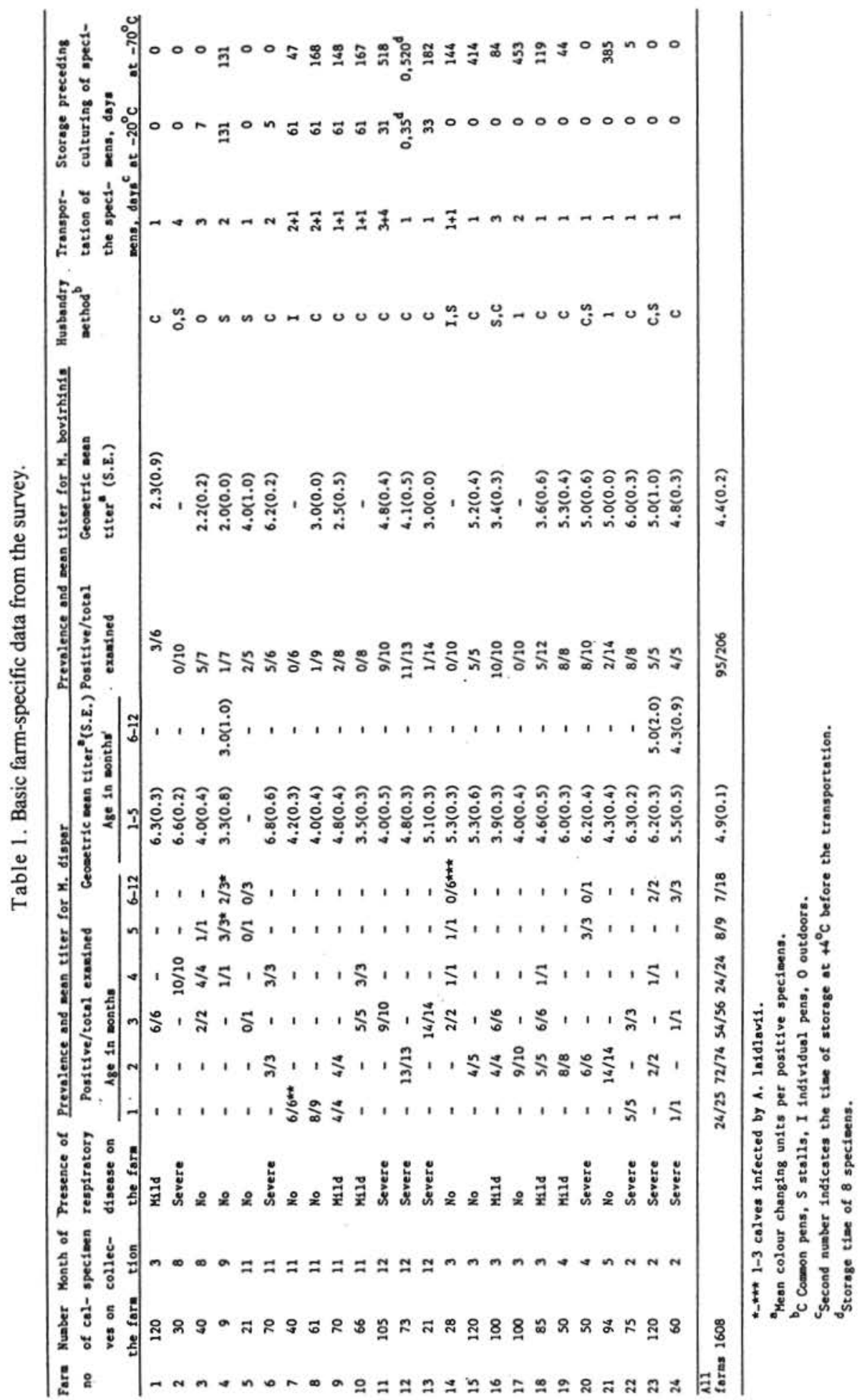


and also due to the chronic course of the disease on most of the farms the distinction between sick and healthy calves at the time of taking specimens was obviously arbitrary and the class "healthy" was probably greatly mixed with subclinical and convalescent cases. A total of 206 calves, $12.8 \%$ of the population, were included in the sample; 188 $(91.3 \%)$ of the calves were 1 to 5 months old ("x months old" means: $\geq x$ and $<x+$ 1) and $18(8.7 \%)$ over 6 months old. The majority were Finnish Ayrshire calves, and the rest Friesian, Finncattle, Charolais or crossbreeds. At the time of specimen collection they were being reared outdoors, in stalls and in individual or common pens (Table 1). Various husbandry types of rearing calves, each specific to age-group, were often practiced on a single farm. The sample contained 5 to 14 calves per farm. When the calves covered by the sample were reared in common pens, containing usually 6 to 10 calves, every 3 to 5 calves were from one pen. When the calves were reared in individual pens, the specimens were often taken from all the calves constituting the agegroup selected for the study. In other words, the sample of calves from a farm was often uniform as regards both age and spatial proximity.

\section{Handling and storage of the specimens}

Nasal swab specimens were taken in a manner described earlier (Tanskanen 1984) in mycoplasma broth and transported, usually within 1 to 2 days, to the laboratory (Table 1). The culturing of 49 specimen broths was made immediately upon arrival or after overnight storage at $+4^{\circ} \mathrm{C}$. Other specimens were stored frozen for variable lengths of time before culturing (Table 1). The initial specimen broths were usually stored after first culture at $-70^{\circ} \mathrm{C}$ enabling possible repetition of the procedure.
Culture and identification of mycoplasmas The glucose calf-serum (GS) medium described by Gourlay \& Leach (1970) with the modifications described earlier (Tanskanen 1984) was used for both transportation and culturing of the specimens. A comparative test with selective media was carried out to test the method used throughout the study for isolating $\mathbf{M}$. dispar and $\mathbf{M}$. bovirhinis from specimens containing their mixed populations (these results will be reported later). For this comparison, one part of the specimens was transported and cultured both in GS-broth and in Hayflick's broth, and another part both in GS-broth and GSbroth supplemented with antiserum to the M. bovirhinis strains PG43 (SGS-broth). These media were prepared as described earlier (Tanskanen 1984). A solid medium was prepared regularly from GS-broth, with the addition of $0.8 \%$ purified Bacto-Agar (Difco).

The methods for isolation and identification of mycoplasmas were the same as described earlier (Tanskanen 1984), except that the specimen broths were not pre-incubated before dilution. Prolonged incubation was used to facilitate the isolation of M. dispar from specimens containing both $\mathrm{M}$. dispar and M. bovirhinis.

The definite identification of isolated mycoplasmas was made by direct epi-immunofluorescence (epi-IF) and growth inhibition (GI) tests, as described earlier (Tanskanen 1984).

\section{Statistical methods}

Logarithmic transformations of titer values were used as bases for statistical analyses of titer levels. Nonparametric tests were applied for statistical analyses. Titers of 2 independent groups were compared using the Mann-Whitney $U$ test. Comparison of the titers of more than 2 groups was car- 
ried out using the Kruskall-Wallis test. The titers of 2 nonindependent groups (Table 3) were compared using the Wilcoxon matched-pairs signed-ranks test (two-way analysis). The isolation frequencies were compared by the chi-square test. The Minitab statistical computing program (Ryan et al. 1982) was used to perform the statistical analyses.

\section{Results}

\section{Species and strains isolated and frequency} of infected farms

Table 2 shows the mycoplasma species found and the frequency of their isolation by nasal swabs with 1 or more of the 3 media used. Mycoplasmas were detected in all 24 farms examined. The most common species was M. dispar, which was isolated from all but 1 of the farms and from $91.7 \%$ of the calves. Other species isolated were M. bovirhinis and A. laidlawii, from 19 and 3 farms, respectively. M. dispar and $\mathbf{M}$. bovirhinis were found to be widely distributed geographically (Fig. 1).

A total of 36 strains, 1 or 2 from each farm, identified as M. dispar according to cultural characteristics and the digitonin test were examined using serological tests. All strains gave positive results both in the epi-IF-test and GI-test with the antiserum to M. dispar strain $462 / 2$. The zone of inhibition in the
GI-test varied from 2 to $12 \mathrm{~mm}$. Correspondingly, all 73 strains identified by cultural characteristics as M. bovirhinis and examined serologically were positive in the epi-IF-test with the antiserum to M. bovirhinis strain PG43. The intensity of staining of 5 of the strains examined was clearly weaker than that of the others. For the same strains only a weak inhibition or none was observed in the GI-test. All the other strains were identified clearly as $\mathbf{M}$. bovirhinis using the GI-test as well. Simultaneous infections by these two antigenically different M. bovirhinis strains were detected using the epi-IF-method in some of the calves. Six digitonin resistent strains, suspected of being acholeplasmas, were identified as A. laidlawii through both of the serological methods above using antiserum to strain PG8.

\section{Correlation of titers for $M$. bovirhinis and $M$. dispar}

Table 3 shows that a significant positive correlation between the titers of $\mathrm{M}$. bovirhinis and M. dispar was found in the comparison of specimens from the 18 farms infected by both species. The highest titer values for each species, in either GS-broth or selective broths, were used for the comparison. It is noteworthy, that about $90 \%$ of the specimens in the 2 highest titer groups were from farms with signs of respiratory disease.

Table 2. Mycoplasmas isolated using nasal swabs from 206 calves on 24 farms ${ }^{\mathrm{a}}$.

\begin{tabular}{lrrrrrrrr}
\hline Species & M. dispar & M. bovirhinis & A. laidlawii & \multicolumn{2}{c}{$\begin{array}{c}\text { One or more of the } \\
\text { named species }\end{array}$} \\
\cline { 5 - 9 } & No & $\%$ & No & $\%$ & No & \% & No & $\%$ \\
\hline $\begin{array}{l}\text { Positive specimens } \\
\text { Positive farms }\end{array}$ & 189 & 91.7 & 107 & 51.9 & 7 & 3.4 & 198 & 96.1 \\
\hline
\end{tabular}

a All the isolations carried out by means of one or more of the different media used are presented. 
Table 3. Comparison of the isolation rates and titer levels of $\mathrm{M}$. bovirhinis and M. dispar using nasal swabs from 1481 - to 5-month old calves on 18 farms found infected by both species.

\begin{tabular}{|c|c|c|c|c|c|}
\hline \multicolumn{4}{|c|}{ Grouping by $\mathrm{M}$. bovirhinis titer $\left(\log _{10} \mathrm{ccu}\right)$} & \multirow{3}{*}{\multicolumn{2}{|c|}{$\begin{array}{c}\text { Geometric mean titer for } \\
\text { M. dispar }{ }^{\text {a }} \text { (S.D.) }\end{array}$}} \\
\hline \multirow[t]{2}{*}{ Groups } & \multirow[t]{2}{*}{$\begin{array}{l}\text { Number of } \\
\text { specimens }\end{array}$} & \multicolumn{2}{|c|}{$\begin{array}{l}\text { Proportion of specimens from } \\
\text { farms with mild or severe disease }\end{array}$} & & \\
\hline & & Number & $\%$ & & \\
\hline $0^{\mathrm{b}}$ & 50 & 26 & 52.2 & & $4.3(1.6)^{c}$ \\
\hline $1-2$ & 11 & 7 & 63.6 & $5.0(0.8)$ & \\
\hline $3-4$ & 28 & 23 & 64.0 & $4.9(1.4)$ & \\
\hline $5-6$ & 50 & 45 & 90.0 & $5.4(1.5)$ & \\
\hline $7-8$ & 9 & 8 & 88.9 & $6.6(1.1)$ & \\
\hline $1-8$ & 98 & 83 & 84.7 & & $5.3(1.5)^{\mathrm{c}}$ \\
\hline $0-8$ & 148 & 109 & 73.6 & & $5.0(1.6)$ \\
\hline
\end{tabular}

${ }^{a}$ Mean $\log _{10}$ colour changing units per all the specimens in a group.

${ }^{\mathrm{b}} 0=$ Negative for $\mathrm{M}$. bovirhinis.

c The titers differ significantly at $\mathrm{p}<0.001$.

Significant positive correlation $(r=0.36, p<0.001)$ was found between the titers for M. bovirhinis and M. dispar.

The level of colonisation by M. dispar and $M$. bovirhinis

Some of the basic farm-specific results are presented in Table 1. In Tables 4 to 6 , the data are classified according to age, association with respiratory disease on the farm, and husbandry type, respectively. In all these tables the titers given are those from cultures in the GS-broth, except for 7 cases, where the result for $\mathbf{M}$. dispar was negative in the GS-broth and was substituted with a positive one obtained in the SGS-broth. The reliability of the remaining 17 negative results for M. dispar was in 12 cases supported by identical results for repeat culturings of the specimens stored at $-70^{\circ} \mathrm{C}$; in 5 cases the specimens had not been stored. The statistical titer comparisons reported in the tables, are all conducted with the exclusion of the negative (zero) calves.

Table 1 shows an average isolation frequency of $97,8 \%$ for M. dispar and a range of
88.9 to $100 \%$ on positive farms among 1 - to 5 -months old calves. The level of colonisation as expressed by the geometric mean titer and SE still varied considerably among the farms. In the case of M. bovirhinis the variation in isolation frequencies and mean titers among the positive farms was much wider.

Age-specific level of colonisation. Table $4 a$ shows the age-specific prevalence and titer distribution of M. dispar infection in the sample of calves from infected farms. A high prevalence and high average titers among 1- to 5-month old calves was demonstrated. A significantly lower prevalence among older calves was noted. Only if negative cases, coded as zero, were included in the analysis, did the titers between the groups of 1- to 5-months old and older calves differ significantly $(\mathrm{p}<0.001)$. The variation in titers was wide within all age- 
Table 4 a. Prevalence and titer of M. dispar in nasal swab specimens from 201 calves located on 23 farms found infected. Grouping with reference to age of calves.

\begin{tabular}{|c|c|c|c|c|c|c|c|c|c|c|c|c|c|c|}
\hline \multirow{3}{*}{$\begin{array}{l}\text { Age in } \\
\text { months }\end{array}$} & \multirow{3}{*}{$\begin{array}{c}\text { Number of } \\
\text { of } \\
\text { farms }\end{array}$} & \multicolumn{10}{|c|}{ Number of calves } & \multirow{3}{*}{$\begin{array}{c}\text { Total } \\
\text { examined }\end{array}$} & \multirow{3}{*}{$\begin{array}{c}\text { Percentage } \\
\text { of positive } \\
\text { calves }\end{array}$} & \multirow{3}{*}{$\begin{array}{l}\text { Geometric mean } \\
\text { titer }^{\mathrm{a}} \\
\text { (S.E.) }\end{array}$} \\
\hline & & \multicolumn{10}{|c|}{ Titer distribution (log10ccu/specimen) } & & & \\
\hline & & 1 & 2 & 3 & 4 & 5 & 6 & 7 & 8 & 9 & $1-9$ & & & \\
\hline 1 & 5 & 0 & 0 & 6 & 6 & 5 & 6 & 1 & 0 & 0 & 24 & 25 & 96.0 & $4.6(0.3)$ \\
\hline 2 & 11 & 1 & 2 & 7 & 9 & 28 & 15 & 8 & 1 & 1 & 72 & 74 & 97.3 & $5.1(0.2)$ \\
\hline 3 & 10 & 0 & 3 & 14 & 5 & 12 & 15 & 5 & 0 & 0 & 54 & 55 & 98.2 & $4.7(0.2)$ \\
\hline 4 & 8 & 0 & 1 & 2 & 3 & 3 & 8 & 6 & 1 & 0 & 24 & 24 & 100.0 & $5.5(0.3)$ \\
\hline 5 & 4 & 0 & 2 & 0 & 3 & 0 & 3 & 0 & 0 & 0 & 8 & 8 & 100.0 & $4.3(0.6)$ \\
\hline $6-12$ & 5 & 0 & 1 & 2 & 2 & 0 & 2 & 0 & 0 & 0 & 7 & 15 & 40.0 & $4.0(0.6)$ \\
\hline $\begin{array}{l}\text { All age- } \\
\text { groups }\end{array}$ & 23 & 1 & 9 & 312 & 28 & 48 & 49 & 20 & 2 & 1 & 189 & 201 & 94.0 & $4.9(0.1)$ \\
\hline
\end{tabular}

${ }^{\text {a }}$ Mean $\log _{10}$ colour changing units per positive specimen.

The isolation rate among 1- to 5-month old calves differed significantly at $\mathrm{p}<0.001$ from that among older ones.

No difference ( $p>0.05$ ) was found between the titer levels of one-month groups of 1 - to 5-month old calves.

groups. M. bovirhinis was isolated in roughly equal frequencies and titers from older and from 1- to 5-month old calves, as shown in Table 4b. Only among 6-month old or older calves was the prevalence for $\mathbf{M}$. bovirhinis higher than that for M. dispar. The $7 \mathrm{~A}$. laidlawii isolations, in titers of 2-5 $\log _{10} \mathrm{ccu}$, were from calves ranging in age from 1 to 12 months (Table 1).

Table 4 b. Prevalence and titer of M. bovirhinis in nasal swab specimens from 161 calves on 19 farms found infected. Grouping with reference to age of calves.

\begin{tabular}{|c|c|c|c|c|c|c|c|c|c|c|c|c|c|}
\hline \multirow{3}{*}{$\begin{array}{l}\text { Age in } \\
\text { months }\end{array}$} & \multirow{3}{*}{$\begin{array}{c}\text { Number of } \\
\text { of } \\
\text { farms }\end{array}$} & \multicolumn{9}{|c|}{ Number of calves } & \multirow{3}{*}{$\begin{array}{c}\text { Total } \\
\text { examined }\end{array}$} & \multirow{3}{*}{$\begin{array}{l}\text { Percentage } \\
\text { of positive } \\
\text { calves }\end{array}$} & \multirow{3}{*}{$\begin{array}{c}\text { Geometric mean } \\
\text { titer }^{\mathrm{a}} \\
\text { (S.E.) }\end{array}$} \\
\hline & & \multicolumn{9}{|c|}{ Titer distribution (log10ccu/specimen) } & & & \\
\hline & & 1 & 2 & 3 & 4 & 5 & 6 & 7 & 8 & $1-8$ & & & \\
\hline 1 & 4 & 0 & 1 & 2 & 0 & 0 & 3 & 2 & 0 & 8 & 19 & 42.1 & $5.0(0.8)$ \\
\hline 2 & 10 & 0 & 4 & 4 & 6 & 14 & 9 & 3 & 1 & 41 & 63 & 65.0 & $4.8(0.2)$ \\
\hline 3 & 9 & 1 & 4 & 9 & 5 & 7 & 4 & 0 & 0 & 30 & 49 & 61.2 & $3.8(0.3)$ \\
\hline 4 & 5 & 0 & 2 & 0 & 0 & 1 & 3 & 0 & 0 & 6 & 10 & 60.0 & $4.5(0.8)$ \\
\hline 5 & 4 & 0 & 0 & 1 & 0 & 1 & 0 & 0 & 0 & 2 & 8 & 25.0 & $4.0(1.0)$ \\
\hline $6-12$ & 5 & 0 & 2 & 1 & 1 & 3 & 0 & 1 & 0 & 8 & 12 & 66.7 & $4.1(0.6)$ \\
\hline $\begin{array}{l}\text { All age- } \\
\text { groups }\end{array}$ & 19 & 1 & 13 & 17 & 12 & 26 & 19 & 6 & 1 & 95 & 161 & 59.0 & $4.4(0.2)$ \\
\hline
\end{tabular}

${ }^{\text {a }}$ Mean $\log _{10}$ colour changing units per positive specimen.

No significant difference $(\mathrm{p}>0.05)$ was found in the age-specific isolation rates or titer levels between the groups. 
The level of colonisation according to farm-specific respiratory disease status. Tables $5 \mathrm{a}$ and $\mathrm{b}$ show that the level of colonisation both for M. dispar and for M. bovirhinis was higher on farms on which severe or mild respiratory disease was present than on farms without any symptoms of clinical illness. A clear difference between the groups could be demonstrated for $\mathbf{M}$. dispar titer levels, but not for isolation frequencies. Only calves below 6 months, the main target group of the studies, were included in this analyses for M. dispar. The difference in mean ages between the groups (Table 5a) is quite unlikely to have any confounding effect. According to experimental results the titer of M. dispar is not expected to increase by age (Tanskanen 1983, 1984). The one-month specific titer level results for the 3 groups by the disease status also clearly support this contention. The mean titers for age groups 1, 2, 3, 4 and 5 months were as follows: on the farms with no disease: 3.8 , $4.3,4.1$ and 4.0; on the mildly diseased farms: $4.3,5.3,4.5$ and 3.5 (the 5 months group lacked) and on the severely diseased farms: $6.0,5.7,4.9,6.6$ and 5.3. As regards to older calves, the same type of association was suggested since 5 out of 7 calves positive for M. dispar, including the 2 with the titer of $6 \log _{10} \mathrm{ccu}$, were from farms nos. 23 and 24 , which had an epidemic of respiratory disease affecting older calves as well (Table 1). On a few severely diseased farms a closer clinical examination was carried out during the collection of specimens and both clinically sick and apparently healthy calves were included in the sample. No clear differences in the titer levels of M. dispar between the 2 groups could be discerned. For example, on farm no. 12 , the titers for 13 calves classified according to symptoms were as follows: $5,5,4,5,6,4,5$ (mean 4.86) for calves with respiratory symptoms;
5 for a calf additionally affected with diarrhoea; and 2, 5, 6, 5, 5 (mean 4.60) for apparently healthy calves. And on farm no. 2, the figures for 10 calves were: $6,7,7,7,7,6$ (mean 6.66) for calves with symptoms both of diarrhoea and respiratory disease, and 6, $6,6,7$ (mean 6.50 ) for apparently healthy calves.

Of the 186 specimens positive for M. dispar (Tables 1 and $5 a), 38$ (20.4\%) were cultured immediately upon arrival or after overnight storage at $+4^{\circ} \mathrm{C}$ ("nonstored" specimens). Of them, 32 were from farms on which severe respiratory disease was present, and 6 from farms with mild disease. For diagnostic and therapeutic purposes immediate culturing of specimens from some of the farms with severe disease was requested. The rest of the specimens were stored frozen for various periods of time before culturing ("stored" specimens). The titers for the unstored specimens were significantly higher than for the stored specimens but, as mentioned above, the former samples also mainly originated from the farms affected by a definite respiratory disease. In order to eliminate a possible confounding through nonstorage, the 38 named specimens were excluded from the analysis as regards the role of a respiratory disease. There was still a significant difference at $\mathrm{p}<0.01$ between the titers of the 3 groups. Of the 148 specimens cultured after varying periods of storage, the specimens from farms with severe disease were stored for the longest period. As for M. bovirhinis, the groups of nonstored and stored specimens were not significantly $(p>0.05)$ different as regards the titer level, but the prevalence of $\mathrm{M}$. bovirhinis among the nonstored specimens was significantly ( $p$ $<0.01)$ higher than that in stored specimens. The trend in isolation frequencies and titers, which characterized the total material as shown in Table $5 \mathrm{~b}$ was observed within 
Table 5 a. Prevalence and titer of M. dispar in nasal swab specimens from 1861 - to 5 -months old calves on 23 farms. Grouping of farms with reference to respiratory disease.

\begin{tabular}{|c|c|c|c|c|c|c|c|c|c|c|c|c|c|c|}
\hline \multirow{3}{*}{ Groups } & \multirow{3}{*}{$\begin{array}{c}\begin{array}{c}\text { Number } \\
\text { of } \\
\text { farms }\end{array}\end{array}$} & \multicolumn{9}{|c|}{ Number of calves } & \multirow{3}{*}{$\begin{array}{l}\text { Total } \\
\text { exam- } \\
\text { ined }\end{array}$} & \multirow{3}{*}{$\begin{array}{c}\text { Percentage } \\
\text { of positive } \\
\text { calves }\end{array}$} & \multirow{3}{*}{$\begin{array}{c}\text { Geometric } \\
\text { mean titer } \\
\text { (S.E.) }\end{array}$} & \multirow{3}{*}{$\begin{array}{l}\text { The mean age of } \\
\text { calves in months } \\
\text { (S.E.) }\end{array}$} \\
\hline & & \multicolumn{9}{|c|}{ Titer distribution (log10 $10 \mathrm{cu} / \mathrm{specimen}$ ) } & & & & \\
\hline & & 1 & 2 & 3 & 45 & 6 & 7 & 8 & 9 & $1-9$ & & & & \\
\hline \multirow{3}{*}{$\begin{array}{l}\text { 1. } \begin{array}{l}\text { No } \\
\text { disease }\end{array} \\
\text { 2. } \begin{array}{l}\text { Mild } \\
\text { disease }\end{array} \\
\text { 3. } \begin{array}{l}\text { Severe } \\
\text { disease }\end{array}\end{array}$} & 8 & 1 & 3 & 13 & 1320 & 4 & 2 & 0 & 0 & 56 & 59 & $94.9^{\mathrm{d}}$ & $4.2(0.2)^{\mathrm{c}}$ & $2.8(1.2)^{d}$ \\
\hline & 6 & 0 & 2 & 12 & 812 & 12 & 6 & 0 & 0 & 52 & 52 & $100.0^{\mathrm{b}}$ & $4.7(0.2)^{\mathrm{c}}$ & $3.0(0.8)^{d}$ \\
\hline & 9 & 0 & 3 & 4 & 516 & 31 & 12 & 2 & 1 & 74 & 75 & $98.7^{\mathrm{b}}$ & $5.6(0.2)^{\mathrm{c}}$ & $3.3(1.0)^{d}$ \\
\hline $\begin{array}{l}\text { All } \\
\text { groups }\end{array}$ & 23 & 1 & 8 & 29 & 2648 & 47 & 20 & 2 & 1 & 182 & 186 & 97.8 & $4.9(0.1)$ & $3.0(1.0)$ \\
\hline
\end{tabular}

${ }^{\text {a }}$ Mean $\log _{10}$ colour changing units per positive specimen.

${ }^{b}$ No significant difference $(p>0.05)$ between the 3 groups.

${ }^{\mathrm{c}}$ Significant difference at $\mathrm{p}<0.001$ between the 3 groups.

${ }^{\mathrm{d}}$ Significant difference at $\mathrm{p}<0.01$ between the 3 groups.

both groups. As classified according to respiratory disease, the titers differed within both groups at $\mathrm{p}<0.05$ and the respective difference in the prevalence of $\mathrm{M}$. bovirhinis was significant at $\mathrm{p}<0.001$ for nonstored and $\mathrm{p}<0.01$ for stored specimens.
The data on 186 calves positive for M. dispar were also stratified with reference to the duration of the transportation of the specimens with a view to the possibility of the confounding differences involved. Differences in the colonisation levels for M. dispar

Table 5 b. Prevalence and titer of M. bovirhinis in nasal swab specimens from 161 calves on 19 farms.

Grouping of farms with reference to respiratory disease.

\begin{tabular}{|c|c|c|c|c|c|c|c|c|c|c|c|c|c|c|}
\hline \multirow{3}{*}{ Groups } & \multirow{3}{*}{$\begin{array}{c}\text { Number } \\
\text { of } \\
\text { farms }\end{array}$} & \multicolumn{9}{|c|}{ Number of calves } & \multirow{3}{*}{$\begin{array}{c}\text { Total } \\
\text { exam- } \\
\text { ined }\end{array}$} & \multirow{3}{*}{$\begin{array}{c}\text { Percentage } \\
\text { of positive } \\
\text { calves }\end{array}$} & \multirow{3}{*}{$\begin{array}{l}\text { Geometric } \\
\text { mean titer } \\
\text { (S.E.) }\end{array}$} & \multirow{3}{*}{$\begin{array}{l}\text { The mean age of } \\
\text { calves in months } \\
\text { (S.E.) }\end{array}$} \\
\hline & & \multicolumn{9}{|c|}{ Titer distribution (log10ccu/specimen) } & & & & \\
\hline & & 1 & 2 & 3 & 4 & 5 & 6 & 7 & 8 & $1-8$ & & & & \\
\hline \multirow{4}{*}{$\begin{array}{l}\text { 1. } \begin{array}{l}\text { No } \\
\text { disease }\end{array} \\
\text { 2. Mild } \\
\text { disease } \\
\text { 3. Severe } \\
\text { disease }\end{array}$} & 6 & 0 & 5 & 3 & 1 & 5 & 2 & 0 & 0 & 16 & 47 & $34.0^{\mathrm{b}}$ & $3.8(0.4)^{c}$ & $3.9(2.8)^{d}$ \\
\hline & 5 & 1 & 3 & 11 & 3 & 7 & 2 & 0 & 0 & 28 & & $650^{b}$ & & $2,\left(077^{d}\right.$ \\
\hline & 3 & 1 & 3 & 11 & 3 & 1 & 2 & 0 & 0 & 28 & 43 & $65.0^{\circ}$ & $3.8(0.3)^{\circ}$ & $2.9(0.7)^{\circ}$ \\
\hline & 8 & 0 & 5 & 3 & 8 & 14 & 15 & 5 & 1 & 51 & 71 & $71.8^{b}$ & $5.0(0.2)^{\mathrm{c}}$ & $3.5(1.8)^{d}$ \\
\hline $\begin{array}{l}\text { All } \\
\text { groups }\end{array}$ & 19 & 1 & 13 & 17 & 122 & 26 & 19 & 6 & 1 & 95 & 161 & 59.0 & $4.4(0.2)$ & $3.5(2.0)$ \\
\hline
\end{tabular}

${ }^{a}$ Mean $\log _{10}$ colour changing units per positive specimen.

$\mathrm{b}, \mathrm{c}$ Significant difference at $\mathrm{p}<0.01$ between the 3 groups.

${ }^{d}$ No significant difference $(p>0.05$ ) between the 3 groups. 
between the 3 classes were still significant at levels of $0.01,0.001$, and 0.001 within the groups with a transportation duration of 1 , $2-3$, and 2-7 days, respectively (the last mentioned includes the former group). In the corresponding analysis for $\mathrm{M}$. bovirhinis, 161 specimens were divided into 2 groups according to the duration of transportation of either 1 or 2-7 days, respectively. The same trend in the isolation frequencies and titers was again observed as in the case of the total material presented in Table $5 \mathrm{~b}$. However, among 105 specimens transported within 1 day, only the isolation frequencies between the 3 groups varied significantly at $\mathrm{p}<0.05$, whereas the difference between the titers was only at the level of 0.1 . In the 2-7 day transportation group, both the prevalences and titers for $\mathrm{M}$. bovirhinis differed at $\mathrm{p}<0.001$ among the 3 classes.

Because of the cluster sampling not only according to farms but also according to groups of calves within farms, the associa- tion of the colonisation level of M. dispar to the respiratory disease was also analysed by comparing the farm-specific geometric mean titers (Table 1) between groups differing with according to the respiratory condition. The mean titers were $4.3,4.9$, and 5.7 $\log _{10} \mathrm{ccu}$ for groups of no disease, mild disease, and severe disease, respectively, an the difference between them was significant at $\mathrm{p}<0.05$. For a corresponding analysis for $\mathrm{M}$. bovirhinis, the negative cases coded as zero were included for the comparison of the titers. No significant difference ( $p>0.05$ ) could be found between the groups.

The level of colonisation according to husbandry type. Table 6 shows that within the sample of 1- to 5-month old calves reared individually, the prevalence for M. dispar was about the same as that among the calves reared in common pens, but the titers were significantly $(p<0.01)$ lower in

Table 6. Prevalence and titer of M. dispar in nasal swab specimens from 186 1- to 5-months old calves on 23 farms. Grouping of calves with reference to husbandry condition.

\begin{tabular}{|c|c|c|c|c|c|c|c|c|c|c|c|c|c|c|c|}
\hline \multirow{3}{*}{$\begin{array}{l}\text { Groups by } \\
\text { husbandry } \\
\text { condition }\end{array}$} & \multirow{3}{*}{$\begin{array}{c}\text { Number } \\
\text { of } \\
\text { farms }\end{array}$} & \multicolumn{10}{|c|}{ Number of calves } & \multirow{3}{*}{$\begin{array}{l}\text { Total } \\
\text { exam- } \\
\text { ined }\end{array}$} & \multirow{3}{*}{$\begin{array}{c}\text { Percentage } \\
\text { of positive } \\
\text { calves }\end{array}$} & \multirow{3}{*}{$\begin{array}{l}\text { Geometric } \\
\text { mean titer }{ }^{a} \\
\text { (S.E.) }\end{array}$} & \multirow{3}{*}{$\begin{array}{l}\text { The mean age of } \\
\text { calves in months } \\
\text { (S.E.) }\end{array}$} \\
\hline & & \multicolumn{10}{|c|}{ Titer distribution (log $10 \mathrm{ccu} /$ specimen) } & & & & \\
\hline & & 1 & 2 & 3 & 4 & 5 & 6 & 7 & 8 & 9 & $1-9$ & & & & \\
\hline
\end{tabular}

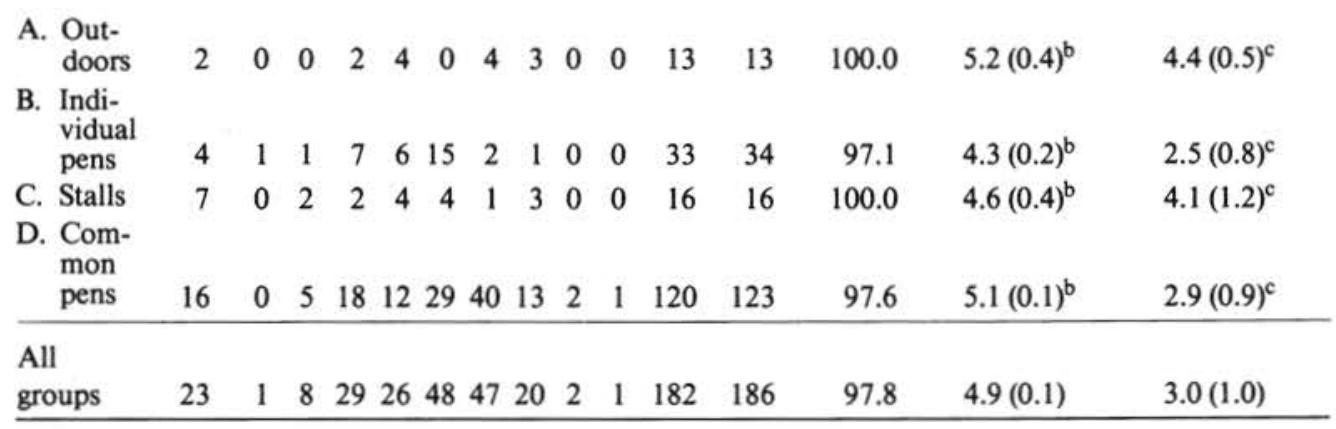

${ }^{a}$ Mean $\log _{10}$ colour changing units per positive specimen.

${ }^{b}$ Difference at $\mathrm{p}<0.05$ between all the groups, and at $\mathrm{p}<0.01$ between groups $\mathrm{B}$ and $\mathrm{D}$.

${ }^{c}$ Difference at $p<0.01$ between all the groups, and at $p<0.01$ between groups $B$ and $D$. 
the former group. As can be seen in Table 1, no signs of respiratory disease were observed on the 4 farms on which the young calves studied were kept in individual pens. Where the youngest group of calves was reared in common pens, mild or severe respiratory disease occurred on 14 of the 16 farms. Of the 34 calves reared in individual pens on 4 different farms, only 2 , both from farm no. 21 , were positive for $\mathrm{M}$. bovirhinis. The isolation rate for $\mathrm{M}$. bovirhinis among the 117 calves reared in common pens on 15 infected farms was $63.2 \%$.

The level of colonisation according to the size of farm. When farms were classified according to size into those with 9 to 50 , 51 to 99 , and 100 or more calves, the geometric mean titers were $4.8,5.2$ and 5.0 $\log _{10}$ ccu for M. dispar, and 2.2, 2.7 and 3.8 $\log _{10}$ ccu for M. bovirhinis, respectively. The differences were not significant $(\mathrm{p}>0.05)$. Negative cases were included in the analysis of the titers for M. bovirhinis.

\section{Discussion}

The main results of the present study were: (i) the high prevalence of M. dispar colonisation both among and within the calf rearing farms; (ii) the high, long-standing and rather homogenous basic level of colonisation within the target age-group; and (iii) the suggested association between a rise in the level of colonisation and the herd respiratory disease. Although the sampling for practical reasons was not formally random, one could be reasonably confident of no serious selection bias in the present context as regards the first two sets of results. Even the third result, framed as a hypothesis, is supported by the following: bias by more conventional factors, as indicated in results and discussed in more detail later, seems to be improbable; the groups are still significantly different when the cluster nature of samples is appreciated in the analyses; the association is in accordance with the results concerning some other respiratory mycoplasmas (Bradbury 1984).

The very high prevalence of farms infected by $\mathrm{M}$. dispar, as demonstrated in the sample of the 24 farms located in various parts of the country, indicates endemicity as well as a high prevalence of infection by this mycoplasma on calf rearing farms in this country in general. It should be pointed out that the target population of the present survey was a special one, and that the results do not apply to other types of population units. The calves were brought to the rearing farms mainly from small dairy farms in the surrounding area, and it is quite seldom that these have been found to be infected by M. dispar (Tanskanen 1987b).

Only a few reports have previously been published on field studies of M. dispar infection in live calves. In their investigation of calf pneumonia in Northern Ireland Bryson et al. (1978a) isolated M. dispar from nasal swabs of calves affected in 45 of the 47 $(95.7 \%)$ outbreaks of clinical pneumonia. A minimum of 6 calves from each outbreak was studied. Ball (1981), however, reported a lower frequency of $35 \%$ for the isolation of M. dispar on 64 farms with clinical cases of calf pneumonia, although, as far as may be inferred from the data presented, the material of this study was partially the same as that of Bryson et al., Gourlay \& Howard (1978) reported isolation of M. dispar from nasopharyngeal swabs taken from 38 of the 41 apparently healthy 1.5 - to 8 -week old calves in the Compton area. Contrary to the above results, Springer et al. (1982) could not isolate $M$. dispar at all from the nasal swabs of 411 clinically normal dairy calves from 20 herds in Lousiana, although the ap- 
propriate medium for the isolation of $\mathbf{M}$. dispar was reportedly used in the study.

Finding M. bovirhinis in $51.9 \%$ of the calves studied, a figure clearly less than that for M. dispar, is, however, largely accordant with the reports of a rather common occurrence of this species in the bovine respiratory tract in several countries (Gourlay \& Howard 1979). Isolations from nasal swab specimens of calves in other countries have varied from a frequency of $5.8 \%$ for a sample of dairy calves (Springer et al. 1982) to $62 \%$ for a group of fattening calves reared for a few weeks after transportation (Jurmanova et al. 1975). The comparatively high percentage of infection found in the present study is evidently associated with the type of calf rearing units sampled in the present survey. The low isolation rate $(3.4 \%)$ for $\mathrm{A}$. laidlawii in the present study is on a par with the results from other countries.

The results of experimental studies indicate that nasal swabbing used in the measurement of M. dispar colonisation represents an unusually effective technique for epidemiological studies of an infection because of the ability of M. dispar detectably, heavily and longstandingly to colonise the respiratory tract of calves (Tanskanen 1983, 1984). The very high prevalence and relatively high titers of M. dispar among the group of 1- to 2-month old calves provides evidence for the high efficiency of this species to spread and colonise the respiratory pathways of young calves also when reared in field conditions. With reference to the setting for transmission it is noteworthy that roughly the same isolation rate was obtained for the calves reared individually as for those reared in common pens. As indicated above, the calves have only quite seldom been found to be infected by $\mathrm{M}$. dispar before transportation to the calf rearing farms (Tanskanen 1987b). An isolation rate of $100 \%$ and an occurrence of high titers in calves even at the age of 4 to 5 months indicates a heavy colonisation of a rather long duration of the respiratory pathway under the field conditions studied. A similar colonisation pattern was found in earlier experimental studies (Tanskanen 1983, 1984). Although the number of older calves examined was relatively small, a significantly lower level of colonisation in these older animals could be demonstrated: a result borne out by experimental data as well (Tanskanen 1983, 1984). The high degree of colonisation extending over several months is obviously well suited to maintaining the infection effectively in larger populations of calves. The observed endemicity is further explained by the open herd type of rearing units and the sporadic replenishment of the population with largely sensitive calves from often small herds in the surroundings. Furthermore, the results show that nasal swabbing of only a few calves of the "indicator age-group" would generally be adequate for detection of herd infection by this agent in calf rearing establishments.

The results for $\mathrm{M}$. bovirhinis show some clear-cut differences when compared to those for M. dispar. The same kind of a decrease-by-age-colonisation-pattern (the difference between $<6$ months- and $\geq 6$ months-groups) as for M. dispar could not be demonstrated and the prevalence in younger age-groups was regularly lower than that for M. dispar. Experimental and field studies (Gourlay \& Howard 1979, Gourlay et al. 1979, Friis 1981, Tanskanen 1984) have suggested that the colonisation by M. bovirhinis is frequently restricted to the upper parts of the respiratory tract, as opposed to M. dispar, which readily colonises the more distal respiratory pathway as well (Thomas \& Smith 1972, Howard et al. 1976, Gourlay et al. 1979, Friis 1980, Tanskanen 1984). In 
addition, in the earlier longitudinal study (Tanskanen 1984), the phase of high level colonisation by $\mathrm{M}$. bovirhinis, detectable by the nasal swab method, was definitely shorter than that for M. dispar. In the later phases $\mathrm{M}$. bovirhinis could often be isolated only irregularly and in small titers from the nasal swabs, although a relatively heavy colonisation of larynx and upper trachea was detected at slaughter. The sensitivity of the nasal swabbing method in the detection of both individual and herd-infection in calves thus appears to be lower for M. bovirhinis than for M. dispar. In the present study the possibility of individual calves and farms being falsely negative for M. bovirhinis has to be recognised, especially when evaluating the results of a low prevalence in a part of the farms studied, and of negativity on 5 of the farms. The wide variation in farm-specific prevalence for M. bovirhinis, presumably to a large extent actual, could well be due partly to factors such as strain differences and rearing conditions. Strain differences were noticed in both this and earlier study (Tanskanen 1984). A lower prevalence of M. bovirhinis was found in the present survey on the farms practicing husbandry with individual pens than on those farms rearing in common pens.

The possible pathogenicity of M. dispar to the bovine respiratory tract is a question of practical importance. A comparative survey of sick and healthy calf populations represents an epidemiological approach to clarification of the problem not often utilised so far. The second stage of the design of the present survey, i.e. the inclusion of diseased in addition to healthy herds in the study, aimed at the possibility of such an analysis. The result of a relatively high level of colonisation by M. dispar, even in calves with no symptoms of clinical respiratory disease, further supports the concept of only poten- tial pathogenicity of this agent. What is important in the present context is that, even if no difference was found between the isolation rates of $\mathrm{M}$. dispar in the 3 types of herds classified according to disease status, a statistically significant increase in the level of colonisation was associated with the occurrence of respiratory disease in a herd. Whereas the just mentioned association with diseased farms was in the first place measured according to the state of calves with clinical symptoms at the time of sampling, no definite difference was found in cases more closely studied between the levels of colonisation of clinically sick and of apparently healthy calves in the age-group sampled. Even in less closely studied instances the level of colonisation found on farms with chronic, severe disease probably reflected a more general hightening of the M.dispar level among the age-group chronically and most clearly affected. Even after the effects of possible confounding factors, such as age, storage, transportation time and herd size were assessed or controlled in the analysis, the correlation still remainded statistically significant and suggestive of biological significance. As to the unlikelihood of any confounding by age in the present results, it should be emphasized that experimentally, in uncomplicated cases of M. dispar colonisation, after a rapid initial rise a plateauphase in titer follows and then in time a gradual decrease takes place (Tanskanen 1984). The somewhat higher average age of calves in the group of severely affected herds probably only reflects the tendency to sample primarily clinically sick calves and their age group; it is reasonable to expect that older calves of the target age group should be affected by chronic respiratory disease with higher frequency than the younger ones. On the other hand, the sampling of calves was adjusted to a phase, distant enough from 
their arrival, when infection and the initial rise of the titer with all likelihood had fully taken place. Thus, the hightened level of colonisation by M. dispar in the calves of a higher average age within the diseased herds supports the suggestion of a causal relationship.

The same basic relationship also applied to M. bovirhinis: i.e., both the prevalence and the level of colonisation were in this case associated with respiratory disease on the farm. Consequently, and this further indicates the relationship stated above, a correlation could be demonstrated between the colonisation levels of $\mathrm{M}$. dispar and those of M. bovirhinis. This correlation was largely determined by the high levels of colonisation on the farms severely affected by respiratory disease.

It remains an open question whether the association between an elevated colonisation level by these organisms and the occurrence and degree of respiratory disease, as demonstrated by the present survey, is of more general relevance and, furthermore, what the role of these mycoplasmas in the disease complex actually is. Clearly, the present results cannot be generalized too far, because the respiratory disease in this study has not been etiologically characterised, but the results at least suggest that an association may exist. A synergistic relationship with certain viruses is well-known with regards to avian respiratory tract mycoplasmas, as was recently reviewed by Bradbury (1984); this relationship is also well-known with regards to mycoplasmas in some other animal species (Kasza et al. 1969; Howard et al. 1978).

More specific questions in the present context are whether and to what extent M. dispar and M. bovirhinis, individually or together, could have a pathogenic influence of their own on cases of respiratory disease initiated by some other agent, or whether they only multiplied above their normal amount, in changed surroundings, without noxious effects. Based on the knowledge of potential pathogenicity of M. dispar under some experimental conditions (Thomas \& Howard 1974, Brownlie et al. 1976, Howard et al. 1976, Gourlay et al. 1979, Friis 1980), it is reasonable to assume that this agent also participated in the process when it was present in higher than normal titers on the definitely diseased farms in the present study. One could construe such a role for M. bovirhinis as well. This concept finds some support in the experimental findings of some pathogenicity of this agent to the udder (Brownlie et al. 1976).

The association of a higher colonisation level with the husbandry type of keeping the calves in common pens most probably reflects a more indirect causal relationship than an association between a higher colonisation level and respiratory disease. The results agree with the commonly accepted concept that aggregation is one of the major primary factors of respiratory disease.

After the completion of the manuscript a study by Rosendal \& Martin (1986) appeared reporting the finding of an association between rise in serological titers for $\mathbf{M}$. dispar and occurrence of undifferentiated respiratory disease in feedlot calves. The named finding, made with a different technique, is considered to support the present result of the suggestive causal relationship between the respiratory disease and an increase in the level of colonisation by $\mathrm{M}$. dispar.

\section{Acknowledgements}

I am deeply indebted to the veterinary surgeons in practice, without whose co-operation this work would not bave been possible. The technical assistance of Miss A. Vehviläinen and Miss T. Loikala is gratefully acknowledged. This study re- 
ceived financial support from The Research Council for Medical Sciences of the Academy of Finland and from the Ministry of Agriculture and Forestry.

\section{References}

Ball HJ: Comparative biochemical studies of respiratory mycoplasmas with particular references to Mycoplasma dispar and Mycoplasma bovirhinis. Ph.D. Thesis, Belfast 1981.

Bitsch V, Friis NF, Krogh HV: A microbiological study of pneumonic calf lungs. Acta vet. scand. 1976, 17, 32-42.

Bocklish $H$, Pfutzner H, Zepezauer $W$, Kuhn $U$, Ludvig $H$-J: Untersuchungen zur Mykoplasmainfektion der Kalbes 1. Mitteilung: Mykoplasmannachweise bei Pneumonien und Arthritiden von Kälbern. (Studies into Mycoplasma infection of calves. First communication: identification of Mycoplasma in calves with pneumonia and arthritis. Arch. exp. Vet.Med. 1983, 37, 435-443.

Bradbury JM: Avian mycoplasma infections: Prototype of mixed infections with mycoplasmas, bacteria and viruses. Ann. Microbiol. (Paris), 1984, 135A, 83-89.

Brownlie J, Howard CJ, Gourlay RN: Pathogenicity of certain mycoplasma species in the bovine mammary gland. Res. Vet. Sci. 1976, 20 , 261-266.

Bryson DG, McFerran JB, Ball HJ, Neill SD: Observations on outbreaks of respiratory disease in housed calves-(1) Epidemiological, clinical and microbiological findings. Vet. Rec. 1978a, 103, 485-489.

Bryson DG, McFerran JB, Ball HJ, Neill SD: Observations on outbreaks of respiratory disease in housed calves-(2) Pathological and microbiological findings. Vet. Rec. 1978b, 103, 503 -509 .

Friis NF: Mycoplasma dispar as a causative agent in pneumonia of calves: Acta vet. scand. 1980, $21,34-42$.

Friis NF: Failure to produce pneumonia in calves by inhalation of Mycoplasma bovirhinis and Ureaplasma aerosols. Acta vet. scand. 1981, 22, 283-285.
Friis $N F$, Krogh $H V$ : Isolation of Mycoplasmas from Danish cattle. Nord. Vet.-Med. 1983, 35, 74-81.

Gourlay RN, Leach RH: A new mycoplasma species isolated from pneumonic lungs of calves (Mycoplasma dispar sp. nov.). J. med. Microbiol. 1970, 3, 111-123.

Gourlay RN, Howard CJ: Isolation and pathogenicity of mycoplasmas from the respiratory tract of calves. In: Respiratory Diseases in Catt't. Ed.: W. B. Martin. Current Top. Vet. Med. 1978, 3, 295-304.

Gourlay RN, Howard CJ: Bovine mycoplasmas. In: The Mycoplasmas. vol. 2. Eds.: J. G. Tully \& R. F. Whitcomb. Academic Press, New York 1979, pp. 49-102.

Gourlay RN, Mackenzie A, Cooper JE: Studies of the microbiology and pathology of pneumonic lungs of calves. J. comp. Path. 1970, 80. 575-584.

Gourlay RN, Thomas LH, Howard CJ: Pneumonia and arthritis in gnotobiotic calves following inoculation with Mycoplasma agalactiae subsp. bovis. Vet. Rec. 1976, 98, 506-507.

Gourlay RN, Howard CJ, Thomas LH, Wyld SG: Pathogenicity of some Mycoplasma and Acholeplasma species in the lungs of gnotobiotic calves. Res. Vet. Sci. 1979, 27, 233-237.

Howard CJ, Gourlay RN, Thomas LH, Stott EJ: Induction of pneumonia in gnotobiotic calves following inoculation of Mycoplasma dispar and ureaplasmas (T-mycoplasmas). Res. Vet. Sci. 1976, 21, 227-231.

Howard CJ, Stott EJ, Taylor G: The effect of pneumonia induced in mice with Mycoplasma pulmonis on resistance to subsequent bacterial infection and the effect of a respiratory infection with Sendai virus on the resistance of mice to Mycoplasma pulmonis. J. gen. Microbial. 1978, 109, 79-87.

Jurmanová K, Kużel M. Menśik J: The role of mycoplasmas in the development of the chronic respiratory syndrome in calves and young cattle. III. The incidence of mycoplasmas in the upper respiratory tract of calves exposed to natural infection in a large-capacity calf house with continuous operation. Docum. vet. $1975,8,403-409$. 
Kasza L, Hodges $R T$, Betts AO, Trexler PC: Pneumonia in gnotobiotic pigs produced by simultaneous inoculation of a swine adenovirus and Mycoplasma hyopneumoniae. Vet. Rec. 1969, 84, 262-267.

Kuniyasu C, Yoshida Y, Ueda H, Sugawara $H$, Ito $Y$ : Isolation of Mycoplasma dispar from pneumonic lungs in Japan. Nat. Inst. Anim. Hlth. Quart. 1977, 17, 75-76.

Langford EV: Mycoplasma agalactiae subsp. bovis in pneumonia and arthritis of the bovine. Can. J. comp. Med. 1977, 41, 89-94.

Muenster OA, Ose EE, Matsuoka T: The incidence of Mycoplasma dispar, Ureaplasma and coventional Mycoplasma in the pneumonic calf lung. Can. J. comp. Med. 1979, 43, 392398.

Rosendal S, Martin SW: The association between serological evidence of mycoplasma infection and respiratory disease in feedlot calves. Can. J. vet. Res. 1986, 50, 179-183.

Ryan TA, Joiner BL, Ryan BF: Minitab reference manual. Duxbury Press., Boston 1982, 154 pp.

Springer WT, Fulton RW, Hagstad HV, Nicholson SS, Garton JD: Prevalence of Mycoplasma and Chlamydia in nasal flora of dairy calves. Vet. Microbiol. 1982, 7, 351-357.

Tanskanen $R$ : Longstanding colonisation of the respiratory tract of calves by Mycoplasma dispar. Acta vet. scand. 1983, 24, 334-336.

Tanskanen $R$ : Colonisation pattern of the respiratory tract of calves by Mycoplasma dispar. Acta vet. scand. 1984, 25, 577-592.

Tanskanen $R$ : Transmissibility of Mycoplasma dispar under experimental conditions. Acta vet. scand. 1987a, 28, 227-240.

Tanskanen $R$ : Transmission of Mycoplasma dispar among calves collected and reared for beef production. Acta vet. scand. 1987b, 28, 241248.

Thomas LH, Smith GS: Distribution of mycoplasmas in the non-pneumonic bovine respiratory tract. J. comp. Path. 1972, 82, 1-4.

Thomas LH, Howard CJ: Effect of Mycoplasma dispar, Mycoplasma bovirhinis, Acholeplasma laidlawii and T-mycoplasmas on explant cultures of bovine trachea. J. comp. Path. 1974, 84, 193-201.
Yamamoto K, Harasawa R, Ogata M, Miura T, Nakane $H$ : Bacteriological examination of bovine pneumonic lungs in Japan. Jap. J. vet. Sci. 1976, 38, 7-14.

\section{Sammendrag \\ Prevalensen och kolonisationsnivå av Myco- plasma dispar och andra mykoplasmer $i$ kalv- uppfödnings besättningar.}

Prevalensen och kolonisationsnivån av respiratoriska mykoplasmer, i synnerhet Mycoplasma dispar (M. dispar), hos kalvar i 24 finländska kalvuppfödnings besättningar undersöktes genom odling av nässekret. Minst 5 kalvar från varje gård undersöktes. Av 206 undersökta kalvar var $91.3 \%$ i ålder 1 till 5 månader. Nio besättningar valdes på grund av diagnosticerade luftvägs besvär, de övriga utan tidigare vetskap om hälsotillstånd.

Alla 24 besättningar och $96.1 \%$ av de undersökta kalvarna visade sig härbörja en eller flere mykoplasma arter. M. dispar, M. bovirhinis och Acholeplasma laidlawii isolerades från 23,19 och 3 besättningar eller från $91.7,51.9$ och $3.4 \%$ av alla undersökta kalvar.

Förekomsten av M. dispar var $97.8 \%$ och de geometriska medelvärdet för titrarna $4.9 \log 10$ colour changing units (ccu) bland $1-5$ månader gamla kalvar i de besmittade besättningarna. Förekomsten $\mathrm{i}$ åldergruppen av 6 till 12 månader gamla kalvar var signifikant lägre $(40 \%)$. En signifikant skillnad på kolonisationsnivån av M. dispar kunde inte påvisas mellan månadsgrupperna inom 1-5 månader gamla kalvar. Den höga kolonisationsgraden bland 1 till 2 månader gamla kalvar indikerar M. dispars goda förmåga att sprida sig och kolonisera luftvägarna hos unga kalvar under omständigheter som beskrives ovan. Det faktum att situationen är densamma hos kalvar i 4 till 5 månaders åldern som hos yngre understöder antagandet att en relativt långvarig och stark kolonisation är utmärkande för denna mykoplasma. Prevalensen av $\mathrm{M}$. bovirhinis bland 1 till 5 månader gamla kalvar var lägre än av M. dispar. En minskning av kolonisationen med M. bovirhinis kunde inte påvisas hos äldre kalvar. Titernivåerna hos både $\mathrm{M}$. dispar och $\mathrm{M}$. bovirhinis var signifikant högre $\mathrm{i}$ besättningar som hade pågående luft- 
vägs lidande än i friska eller i mindre grad angripna besättningar. Samma förhållande kunde fastställas då man jämförde uppfödningssättet, gemensamma boxar med enskilda boxar. Ett kausalsammanhang mellan kolonisationsnivån och luftvägslidandet, vilkendera antingen som orsak eller verkan, framkastas, liksom ett mera indirekt kausalsammanhang med uppstallningen i de gemensamma boxarna.

\section{(Received December 23, 1986).}

Reprints may be requested from: Raili Tanskanen, Department of Microbiology and Epizootology, College of Veterinary Medicine, P. O. Box 6, SF-00551 Helsinki 55, Finland. 